\title{
New records and a review of the Chironomidae (Diptera) of Kuwait and the United Arab Emirates
}

\author{
Will K. Reeves ${ }^{1}$ and John H. Epler ${ }^{2}$ \\ ${ }^{1}$ USDA - APHIS -BRS-WCAB, 2150 Centre Ave., Bldg. B, Ft. Collins, CO 80526-8117, USA. \\ E-mail:wkreeves@gmail.com \\ 2461 Tiger Hammock Road, Crawfordville, FL 32327, USA. E-mail: johnepler3@comcast.net
}

The Chironomidae of the western Arabian Peninsula were reviewed with keys, collection sites, and minor descriptions of 53 species by Cranston (1989) and Cranston and Judd (1989), with additional records and new species described by Al-Houty (1997), Andersen and Mendes (2010), and Giłka (2009). Despite the large land area, the number of reported species is small, most likely because the land is extremely arid and freshwater habitats are rare. Kuwait and the United Arab Emirates are hot, dry, desert countries in the Arabian Peninsula and aquatic habitats are of great interest to people living in these desert countries. In Kuwait agricultural practices produce the majority of temporary aquatic habitats that support aquatic insects (Salit et al. 1996) as there are very few natural surface freshwater sources. The United Arab Emirates likewise has very little natural freshwater. We present new records and review the past publications to produce lists of Chironomidae for Kuwait and the United Arab Emirates.

The US Air Force maintains several military bases in Kuwait and the United Arab Emirates. These bases often treat wastewater and dispose of it in retention ponds handling over 600000 litres of water per day. The ponds support extensive vegetation including several species of Phragmites and flowering Asteraceae. They produce thousands of mosquitoes and other aquatic Diptera. Base personnel survey for mosquitoes using miniature light traps and all of the insects trapped on bases are killed by freezing and shipped dry to the US Air Force School of Aerospace Medicine at Wright-Patterson AFB, OH for identification. Mosquitoes are the surveillance target and represent more than $99 \%$ of the total catch. Collection sites in Kuwait were at Ali Al Salem Air Base near Kuwait City at 29.36 $\mathrm{N}, 47.52^{\circ} \mathrm{E}$, Ahmed Al Jaber Air Base near Kaba at $28.95^{\circ} \mathrm{N}, 47.79^{\circ} \mathrm{E}$, and in the United Arab Emirates at Al Dhafra Air Base near Abu Dhabi at 24.26 $6^{\circ}$, $54.56^{\circ}$ E. Chironomidae were stored for later study because they are not of immediate medical significance. Several species can be pests and to the untrained resemble mosquitoes. An assessment was made in May 2016 of possible predatory Diptera in the water treatment ponds and of the non-target organisms for pesticide treatments. All of the adult Chironomidae stored in collections from two bases in Kuwait and one from the United Arab Emirates were sorted and identified. Material that had been dried, and material that had been dried and then placed in alcohol, was less than satisfactory, with few specimens with antennae and all legs intact. Specimens were dissected (or re-assembled) and either mounted directly in Euparal or cleared in lactic acid and then mounted in Euparal. Keys and descriptions for species in the region were used for identification (Andersen and Mendes 2010, Cranston 1989, Cranston and Judd 1989, Ekrem 1999, 2001, Fittkau 1962, Freeman 1955, 1956, 1957, 1959, Giłka 2009, Saether 1990). Specimens are in the J.H. Epler Collection and will be deposited in the Florida State Collection of Arthropods.

\section{Historic Records}

Previously reported species by Al-Houty (1997), Cranston (1989), Cranston and Judd (1989), Andersen and Mendes (2010), and Giłka (2009) and these along with the new records are presented in Table 1.

Al-Houty (1997) listed three species for Kuwait, but it is extremely doubtful that Chironomus dorsalis occurs in Kuwait. She listed many taxonomists that identified the insects listed in the paper; among them was P.S. Cranston, the only midge specialist. Upon checking with Cranston, he could not recall any details but did not think that he would have identified C. dorsalis from Kuwait (Cranston pers. comm., 28.vii.2016). Thus we do not consider this species in our list. The other two species she listed have been recorded from Saudi Arabia (Cranston \& Judd 1989) and are included here.

With the exception of Polypedilum (Polypedilum) nubifer and Zavrelimyia vaillanti from the United Arab Emirates, our records represent new country level reports. Based on published reports and our collections the known chironomid fauna of Kuwait contains seven species and the United Arab Emirates is represented by 31 species. 
Two species identified in the collections represent undescribed species. There were not enough specimens and the condition of the material was not good enough to describe them. The Cricotopus sp. "Kuwait" is most similar to Cricotopus flavozonatus Freeman, 1953. Cricotopus larvae are usually associated with aquatic plants and algae, where they feed on plant material, algae and diatoms. The Tanytarsus sp. "UAE" was most similar to Tanytarsus minutipalpus Ekrem \& Harrison, 1999. The genitalia of T. sp. "UAE" are very similar to those of T. minutipalpus, but the palps are basically normal. It has an AR of 1.36, scutal tubercle, wing with setae in cells r $4+5, \mathrm{~m} \mathrm{1+2}$. Tanytarsus larvae are detritus/plant feeders. Further collections could produce enough material to describe these species.

\section{New records}

\section{Kuwait}

Ali Al Salem Air Base

Cricotopus sp. "Kuwait" 17 March 2016, 27 Feb. 2016

Chironomus calipterus 27 Feb. 2016

Chironomus pulcher 17 February 2014, 27 February 2016, 17 March 2016

Polypedilum (Polypedilum) nubifer 17 March 2016

Ahmed Al Jaber Air Base

Limnophyes natalensis 7-27 April 2016

Chironomus calipterus 7-27 April 2016

Polypedilum (Polypedilum) nubifer 7-27 April 2016

\section{United Arab Emirates}

Al Dhafra Air Base

Zavrelimyia vaillanti 23 February 2014

Polypedilum (Tripodura) aegyptium 23 February 2014

Polypedilum (Polypedilum) nubifer 23 February 2014

Tanytarsus sp. "UAE" 23 February 2014

Table 1: Checklist of historical records of Chironomidae reported in Kuwait and the United Arab Emirates (UAE) along with newly reported species from 2014-2016.

\begin{tabular}{lll}
\hline Species & Country & Reported by \\
\hline Tanypodinae & & \\
Ablabesmyia (Ablabesmyia) longistyla Fittkau, 1962 & UAE & Andersen and Mendes (2010) \\
Djalmabatista reidi (Freeman, 1955) & UAE & Andersen and Mendes (2010) \\
$\begin{array}{l}\text { Procladius (Holotanypus) apicalis (Kieffer, 1918) } \\
\text { Procladius (Holotanypus) brevipetiolatus }\end{array}$ & UAE & Andersen and Mendes (2010) \\
$\begin{array}{l}\text { (Goetghebuer, 1935) } \\
\text { Paramerina vaillanti Fittkau, 1962 }\end{array}$ & Kuwait & Al-Houty (1997) \\
Zavrelimyia vaillanti (Fittkau, 1962) & UAE & Andersen and Mendes (2010)
\end{tabular}


Orthocladiinae

Bryophaenocladius clavatus Andersen \& Mendes, 2010

Bryophaenocladius rostratus Andersen \& Mendes, 2010

Cricotopus sp. "Kuwait"

Limnophyes natalensis (Kieffer, 1914)

Psectrocladius (Psectrocladius) limbatellus (Holmgren, 1869)

Pseudosmittia danconai Marcuzzi, 1947

Chironominae

Baeotendipes ovazzai (Freeman, 1957)

Chironomu dorsalis Meigen, 1818

Chironomus calipterus Kieffer, 1908

Chironomus ovazzai (Freeman, 1957)

Chironomus pulcher Wiedemann, 1930

Cladotanytarsus pseudomancus (Goetghebuer, 1934)

Cladotanytarsus sagittifer Giłka, 2009

Cryptochironomus rostratus Kieffer, 1921

Dicrotendipes gilkai Andersen \& Mendes, 2010

Dicrotendipes pallidicornis (Goetghebuer, 1934)

Dicrotendipes peringueyanus Kieffer, 1924

Kiefferulus disparilis (Goetghebuer, 1936)

Microchironomus tener (Kieffer, 1918)

Paratanytarsus praecellens Giłka, 2009

Paratendipes nudisquama (Edwards, 1929)

Polypedilum (Polypedilum) alticola Kieffer, 1913

Polypedilum (Polypedilum) nubifer (Skuse, 1889)

Polypedilum nubeculosum (Meigen, 1804)

Polypedilum (Tripodura) aegyptium

Kieffer, 1925

Polypedilum (Tripodura) bifurcatum Cranston, 1989

Polypedilum (Tripodura) harteni Andersen \& Mendes, 2010
UAE Andersen and Mendes (2010)

UAE Andersen and Mendes (2010)

Kuwait This study

Kuwait This study

UAE Andersen and Mendes (2010)

UAE Andersen and Mendes (2010)

UAE Andersen and Mendes (2010)

Kuw a it

(Dubious Al-Houty (1997)

record)

Kuwait, Cranston and Judd (1989), Andersen and Mendes (2010), This study

UAE Andersen and Mendes (2010)

Kuwait This study

UAE Giłka (2009)

UAE Giłka (2009)

UAE Andersen and Mendes (2010)

UAE Andersen and Mendes (2010)

UAE Andersen and Mendes (2010)

UAE Andersen and Mendes (2010)

UAE Andersen and Mendes (2010)

UAE Andersen and Mendes (2010)

UAE Giłka (2009)

UAE Andersen and Mendes (2010)

UAE Andersen and Mendes (2010)

Kuwait, Andersen and Mendes (2010), UAE This study

Kuwait Al-Houty (1997)

UAE This study

UAE Andersen and Mendes (2010)

UAE Andersen and Mendes (2010) 


$\begin{array}{lll}\text { Polypedilum (Tripodura) malickianum Cranston, 1989 } & \text { UAE } & \text { Andersen and Mendes (2010) } \\ \text { Tanytarsus formosanus Kieffer, 1912 } & \text { UAE } & \text { Giłka (2009) } \\ \text { Tanytarsus mcmillani Freeman, 1958 } & \text { UAE } & \text { Giłka (2009) } \\ \text { Tanytarsus trifidus Freeman, 1958 } & \text { UAE } & \text { Giłka (2009) } \\ \text { Tanytarsus sp. "UAE" } & \text { UAE } & \text { This study } \\ \text { Virgatanytarsus arduennensis (Goetghebuer, 1922) } & \text { UAE } & \text { Giłka (2009) }\end{array}$

\section{Acknowledgements}

We thank the public health and civil engineering airmen from the US Air Force for collecting and submitting insects. The views expressed in this article are those of the authors and do not necessarily reflect the official policy or position of the Air Force, the Department of Defense, the Department of Agriculture or the U.S. Government.

\section{References}

Al-Houty, W. 1997. Checklist of the insect fauna of Kuwait. - Kuwait Journal of Science and Engineering 24: $145-162$.

Andersen, T. and Mendes, H.F. 2010. Order Diptera, family Chironomidae (with the exception of the tribe Tanytarsini). In Harten, A. van (Ed.) Arthropod fauna of the United Arab Emirates. Vol. 3. Dar Al Ummah, Abu Dhabi, pp. 564-598.

Cranston, P.S. 1989. New species of Chironominae (Diptera: Chironomidae) from Saudi Arabia and the adjacent Middle East. - Fauna of Saudi Arabia 10: 225-235.

Cranston, P.S. and Judd, D.D.. 1989. Diptera: Fam. Chironomidae of the Arabian Peninsula. - Fauna of Saudi Arabia 10: 236-289.

Ekrem, T. 2001. A review of Afrotropical Tanytarsus van der Wulp (Diptera: Chironomidae). - Tijdschrift voor Entomologie 144: 5-40.

Ekrem, T. and Harrison, A.D. 1999. Tanytarsus minutipalpus spec. nov. from the saline lakes in the Rift Valley, East Africa. - Spixiana 22: 199-208.

Fittkau, E.J. 1962. Die Tanypodinae (Diptera: Chironomidae) (Die Tribus Anatopyniini, Macropelopiiniund Pentaneurini). - Abhandlungen zur Larvalsystematik der Insekten 62: 1-453.

Freeman, P. 1955. A study of the Chironomidae (Diptera) of Africa south of the Sahara Part I. - Bulletin of the British Museum (Natural History) Entomology 4: 1-67.

Freeman, P. 1956. A study of the Chironomidae (Diptera) of Africa south of the Sahara Part II. - Bulletin of the British Museum (Natural History) Entomology 4: 287-368.

Freeman, P. 1957. A study of the Chironomidae (Diptera) of Africa south of the Sahara Part III. - Bulletin of the British Museum (Natural History) Entomology 5: 323-426.

Freeman, P. 1959. A study of the Chironomidae (Diptera) of Africa south of the Sahara Part IV. - Bulletin of the British Museum (Natural History) Entomology 6: 13-363.

Giłka, W. 2009. Order Diptera, family Chironomidae tribe Tanytarsini. In Harten, A. van (Ed.) Arthropod fauna of the United Arab Emirates. Vol. 2. Dar Al Ummah, Abu Dhabi, pp. 667-682.

Salit, A.M., Al-Tubiakh, S.S., El-Fiki, S.A. and Enan, O.H. 1996. Physical and chemical properties of different types of mosquito aquatic breeding places in Kuwait State. - Proceedings of the Second International Conference on Urban Pests 2: 185-193.

Sæther, O. A. 1990. A review of the genus Limnophyes Eaton from the Holarctic and Afrotropical regions (Diptera: Chironomidae, Orthocladiinae). - Entomologica scandinavica Supplement 35: 1-139. 